\title{
Women's Readiness to Conduct Pap Smear Test at Primary Health Care Centers in Baghdad City: The Health Belief Model as A Theoretical Framework
}

\author{
Heba Khudair Abbas ${ }^{1}$, Arkan Bahlol Naji \\ ${ }^{1} \mathrm{MScN}(\mathrm{c})$, Research Scholar, University of Baghdad, College of Nursing, \\ ${ }^{2}$ Professor (PhD), University of Baghdad, College of Nursing, Community Health Nursing Department
}

\begin{abstract}
Background: Cervical cancer is the second leading cause of cancer deaths in low and middle-income countries. The International Agency for Research on Cancer (IARC) gauges that the frequency of cervical disease will increment by $75 \%$ worldwide by 2030 .
\end{abstract}

Method: This descriptive correlational study was carried out to examine women's readiness to perform Pap smear test. to (1) assess women's readiness to perform Pap Smear test, (2) identify the association between woman's age, family's socioeconomic status, gravidity, parity, abortion, and their Stages of Change for conducting Pap Smear test, the Perceived Susceptibility to contract cervical cancer, the Perceived Seriousness of cervical cancer, the Perceived Barriers to conduct Pap Smear test, the Perceived Benefits of conducting Pap Smear Test, and the Health Motivation to conducting Pap Smear Test, and (3) investigate the differences in the Perceived Susceptibility to contract cervical cancer, the Perceived Seriousness of cervical cancer, the Perceived Barriers to conduct Pap Smear test, the Perceived Benefits of conducting Pap Smear Test, and the Health Motivation to conducting Pap Smear Test between the groups of the Stages of Change for conducting Pap Smear test woman's level of education, family's socioeconomic class, and family type.

Results: The target population of this study was selected from adult, married women on social media. The SR used a self-reported online survey for data collection. The SR prepared the online survey and published its link on the social media pages and groups, where the study objectives were demonstrated to study subjects

Conclusion: Most of the women are precontemplators. The older the age, the greater the Susceptibility to contracting cervical cancer and the better the family's socioeconomic status, the greater the greater Susceptibility to contracting cervical cancer.

Keywords: Theoretical Framework, Health Belief Model, Women's Readiness, Pap Smear.

\section{Introduction}

Cervical cancer is the second leading cause of cancer deaths in low and middle-income countries ${ }^{(1)}$. In Iraq,cervical disease is the twelfth malignant growth among ladies and the tenth among ladies somewhere in the range of 15 and 44 years old. The annual incidence is 1.2 per 100,000 and mortality rate of cervical cancer is estimated at 1.4 per 100,000 and there is rising threat to $0.3 \%$ for women in all her life. In Asia, the region which Iraq belongs, about $2.5 \%$ of female in the country are exposure to cervical HPV-16/18 infections during aperiod of time and $72 \%$ of invasive cervical cancers are documented to HPVs 16 or 18. Nononcogenic subtypes of HPV, e.g., 6 and 11, lead to low-grade cervical lesions and genital warts ${ }^{(2)}$. These lesions if left long period without treatment, patients contact to high risk to HPV, so these cases must follow up and testing for HPV DNA, colposcopic evaluation and biopsy which preventcervical disease. gauges demonstrate that consistently 311 ladies are determined to have cervical malignancy and 212 pass on from the sickness (USAID, 2013). In view of the public program, Pap smear is offered to all ladies after marriage in medical services places gratis. This was accomplished for three back to back years, and if three ordinary Pap smear tests were gotten, after that this test ought to be rehashed like clockwork ${ }^{(4)}$. 
Fitting that programming may expect organizers to consider different models or speculations when they create projects and intercessions to help way of life conduct changes. A blend of approaches assists with offering the best help and direction to people, gatherings and networks as they work to create sound way of life $\operatorname{practices}^{(5)}$.

\section{Method}

The study design for this study is descriptive predictive design. The descriptive design can be used to predict the value of one variable based on the values obtained for another variable or variables. Prediction is one approach for examining causal relationships between variables. The study was conducted at across Iraq by an online survey. The study included a non-probability, convenience sample of adult women. The SR prepared the online survey and published its link on the social media pages and groups, where the study objectives were demonstrated to study subjects. The target population of this study was selected from adult, married women on social media. The SR used a self-reported online survey for data collection. Data were collected for the period from February $20^{\text {th }}, 2020$ to March 31 $1^{\text {st }}, 2020$.

Data were collected through a self-report instrument that includes First part:The study instrument includes the socio-demographic sheet, the body mass index (BMI), and Second part: the Mental Health Belief Model AssessmentThe Perceived Susceptibility Scale, The Perceived Benefits Scale, Self-Efficacy Scale, Health Motivation, The Perceived Severity Scale, and The Perceived Barriers Scale. Participants indicate how much they agree or disagree with each statement on a scale of 1 to 5 ( 1 = strongly disagree, $2=$ Disagree, 3 $=$ neutral, $4=$ agree, $5=$ strongly agree). Higher scores indicate stronger feelings regarding that construct. This scale originally demonstrated fair to very good internal consistency reliability. The Health Belief Model Scale for Cervical Cancer and the Pap Smear also demonstrated excellent discriminant validity ${ }^{(6)}$. Data were analyzed using the Statistical Package for the Social Sciences (SPSS) for Windows, version 26, Chicago, IL. The statistical measures of frequency, percent, mean, standard deviation were used. The inferential statistical measures of Chi-square, and one-way analysis of variance (ANOVA) were used.

\section{Results}

Table 1. Participants' socio-demographic characteristics $(N=380)$

\begin{tabular}{|l|c|c|}
\hline Variable & Frequency & Percent \\
\hline Age (Years) & 145 & 37.4 \\
$16-24$ & 192 & 49.5 \\
$25-33$ & 39 & 10.1 \\
$34-42$ & 12 & 3.0 \\
$43-52$ & 27.13 & 6.27 \\
\hline Mean (SD) & & \\
\hline Number of children in the family & 56 & 14.4 \\
None & 82 & 21.1 \\
1 & 91 & 23.5 \\
2 & 57 & 14.7 \\
3 & 36 & 9.3 \\
4 & 33 & 8.5 \\
5 & 15 & 3.9 \\
6 & 10 & 2.6 \\
7 & 8 & 2.0 \\
$\geq 8$ & & \\
\hline SE Status & 97 & 25.0 \\
Upper lower class & 129 & 33.3 \\
Lower middle class & 151 & 38.9 \\
Upper middle class & 11 & 2.8 \\
Upper class & & \\
\hline
\end{tabular}

The age mean is $27.13 \pm 6.27$; around a half age 25 -33-years (n $=192 ; 49.5 \%)$, followed by those who age 16-24-years $(n=145$; $37.4 \%)$, those who age $34-42$-years $(n=39 ; 10.1 \%)$, and those who age 43-52-years $(n=12 ; 3.0 \%)$.

Regarding the number of children in the family, less than a quarter reported that they have two children ( $\mathrm{n}=$ 91; 23.5\%), followed by those who have one child ( $\mathrm{n}$ $=82 ; 21.1 \%)$, those who have three children $(\mathrm{n}=57$; $14.7 \%)$, those who do not have a child $(n=56 ; 14.4 \%)$, those who have four children $(\mathrm{n}=36 ; 9.3 \%)$, those who have five children $(n=33 ; 8.5 \%)$, those who have six children $(\mathrm{n}=15 ; 3.9 \%)$, those who have seven children $(\mathrm{n}=10 ; 2.6 \%)$, and those who have eight or more children $(n=8 ; 2.0 \%)$.

Regarding the family's socioeconomic class, less than two-fifth are classified in the upper middle class ( $\mathrm{n}=151 ; 38.9 \%$ ), followed by those who are classified in the lower middle class $(\mathrm{n}=129 ; 33.3 \%)$, those who are classified in the upper lower class $(n=97 ; 25.0 \%)$, and those who are classified in the upper class $(\mathrm{n}=11$; $2.8 \%)$. 
Table 2. Women's distribution according to readiness to perform Pap smear test

\begin{tabular}{|l|c|c|}
\hline $\begin{array}{l}\text { Readiness to perform Pap } \\
\text { smear test }\end{array}$ & Frequency & Percent \\
\hline Precontemplation & 263 & 67.8 \\
Contemplation & 78 & 20.1 \\
Preparation & 12 & 3.1 \\
Action & 13 & 3.4 \\
Maintenance & 8 & 2.1 \\
Termination & 14 & 3.6 \\
\hline
\end{tabular}

Around two-fifth are within normal weight-toheight ratio $(n=153 ; 39.4 \%)$, followed by those who are overweight ( $\mathrm{n}=142 ; 36.6 \%)$, those who have obesity class I $(\mathrm{n}=55 ; 14.2 \%)$, those who have obesity class II $(\mathrm{n}=17 ; 4.4 \%)$, those who have obesity class III $(\mathrm{n}=11$; $2.8 \%)$, and those who are underweight $(n=10 ; 2.6 \%)$.

Table 3. Correlations among study variables

\begin{tabular}{|c|c|c|c|c|c|c|c|c|c|}
\hline & 1. & 2. & 3. & 4. & 5. & 6. & 7. & 8. & 9. \\
\hline \multicolumn{10}{|l|}{ 1. Age } \\
\hline 2. Number of children in the family & $.111^{*}$ & & & & & & & & \\
\hline 3. Socioeconomic Status & .016 & -.028 & & & & & & & \\
\hline 4. BMI & $.271^{* *}$ & .027 & -.019 & & & & & & \\
\hline 5. Benefits of Pap Smear Test and Health Motivation & .035 & .061 & .043 & .024 & & & & & \\
\hline 6. Barriers to Pap Smear Test & .035 & .029 & -.043 & -.032 & $.167^{* *}$ & & & & \\
\hline 7. Perceived Seriousness of Cervical Cancer & .071 & -.006 & -.040 & .045 & .051 & .004 & & & \\
\hline 8. Susceptibility to Cervical Cancer & $.106^{*}$ & -.051 & $.110^{*}$ & .048 & .042 & -.098 & $.264^{* *}$ & & \\
\hline 9. Health Motivation & -.012 & .016 & -.009 & .050 & $.373^{* *}$ & .060 & $.108^{*}$ & .006 & $=$ \\
\hline
\end{tabular}

There is a statistically significant positive correlation between women's age and their Susceptibility to contracting cervical cancer $(r=.106$; at $\mathrm{p}<0.05)$. There is a statistically significant positive correlation between family's socioeconomic status and their Susceptibility to contracting cervical cancer $(\mathrm{r}=.110$; at $\mathrm{p}<0.05)$.

Table 4. Difference in Health Belief Model constructs among readiness to Pap smear test groups

\begin{tabular}{|c|c|c|c|c|c|c|}
\hline \multicolumn{7}{|c|}{ ANOVA } \\
\hline & & Sum of Squares & df & Mean Square & $\mathbf{F}$ & Sig. \\
\hline \multirow{3}{*}{$\begin{array}{l}\text { Benefits of Pap Smear Test and Health } \\
\text { Motivation }\end{array}$} & Between Groups & 197.092 & 5 & 39.418 & 1.768 & .119 \\
\hline & Within Groups & 8518.916 & 382 & 22.301 & & \\
\hline & Total & 8716.008 & 387 & & & \\
\hline \multirow{3}{*}{ Barriers to Pap Smear Test } & Between Groups & 90.608 & 5 & 18.122 & .258 & .936 \\
\hline & Within Groups & 26806.101 & 382 & 70.173 & & \\
\hline & Total & 26896.709 & 387 & & & \\
\hline \multirow{3}{*}{ Perceived Seriousness of Cervical Cancer } & Between Groups & 245.537 & 5 & 49.107 & 1.067 & .378 \\
\hline & Within Groups & 17578.906 & 382 & 46.018 & & \\
\hline & Total & 17824.443 & 387 & & & \\
\hline \multirow{3}{*}{ Susceptibility to Cervical Cancer } & Between Groups & 32.491 & 5 & 6.498 & .932 & .460 \\
\hline & Within Groups & 2663.870 & 382 & 6.973 & & \\
\hline & Total & 2696.361 & 387 & & & \\
\hline
\end{tabular}




\begin{tabular}{|l|l|c|c|c|c|c|}
\hline \multicolumn{9}{|c|}{ ANOVA } & Sum of Squares & df & Mean Square & F & Sig. \\
\hline \multirow{4}{*}{ Health Motivation } & Between Groups & 52.475 & 5 & 10.495 & 1.441 & .209 \\
\cline { 2 - 8 } & Within Groups & 2782.185 & 382 & 7.283 & & \\
\cline { 2 - 8 } & Total & 2834.660 & 387 & & & \\
\hline
\end{tabular}

There is no statistically significant difference in the Health Belief Model constructs among readiness to Pap smear test groups.

Table 5. Difference in Health Belief Model constructs among SE Status groups

\begin{tabular}{|c|c|c|c|c|c|c|}
\hline \multicolumn{7}{|c|}{ ANOVA } \\
\hline & & Sum of Squares & df & Mean Square & $\mathbf{F}$ & Sig. \\
\hline \multirow{3}{*}{$\begin{array}{l}\text { Benefits of Pap Smear Test and Health } \\
\text { Motivation }\end{array}$} & Between Groups & 137.801 & 3 & 45.934 & 2.056 & .106 \\
\hline & Within Groups & 8578.207 & 384 & 22.339 & & \\
\hline & Total & 8716.008 & 387 & & & \\
\hline \multirow{3}{*}{ Barriers to Pap Smear Test } & Between Groups & 66.968 & 3 & 22.323 & .319 & .811 \\
\hline & Within Groups & 26829.741 & 384 & 69.869 & & \\
\hline & Total & 26896.709 & 387 & & & \\
\hline \multirow{3}{*}{ Perceived Seriousness of Cervical Cancer } & Between Groups & 104.502 & 3 & 34.834 & .755 & .520 \\
\hline & Within Groups & 17719.941 & 384 & 46.146 & & \\
\hline & Total & 17824.443 & 387 & & & \\
\hline \multirow{3}{*}{ Susceptibility to Cervical Cancer } & Between Groups & 15.177 & 3 & 5.059 & .725 & .538 \\
\hline & Within Groups & 2681.184 & 384 & 6.982 & & \\
\hline & Total & 2696.361 & 387 & & & \\
\hline \multirow{3}{*}{ Health Motivation } & Between Groups & 3.305 & 3 & 1.102 & .149 & .930 \\
\hline & Within Groups & 2831.355 & 384 & 7.373 & & \\
\hline & Total & 2834.660 & 387 & & & \\
\hline
\end{tabular}

There is no statistically significant difference in the Health Belief Model constructs among SE status groups.

\section{Discussion}

Most are in the Precontemplation Stage of Change $(n=263 ; 67.8 \%)$, followed by those who are in the Contemplation Stage of Change $(n=78$; $20.1 \%$ ), those who are in the Termination Stage of Change $(\mathrm{n}=14 ; 3.6 \%)$, those who are in the Action Stage of Change $(n=13 ; 3.4 \%)$, those who are in the Preparation Stage of Change $(n=12 ; 3.1 \%)$, and those who are in the Maintenance Stage of Change $(n=8$; 2.1\%). These findings reflect that study subjects do not realize how severe the cervical cancer is and how important performing the Pap smear is in detecting the potential cervical cancer in early time. These finding are consistent with that obtained by $\mathrm{Krok}^{(7)}$ who stated that women $(84.4 \%)$ at Visit 1 were categorized in the
Contemplation or Preparation Stages of Change, and $(15.6 \%)$ women were in the Precontemplation Stage of Change and Kwak, ${ }^{(8)}$ who concluded that $15.5 \%$ of women were in the Precontemplation SOC, $21.3 \%$ in the Contemplation, $31.3 \%$ in the Action, $15.4 \%$ in Maintenance, $10.4 \%$ in the Relapse risk, and $6.1 \%$ in the Relapse SOC; Abdullah and Su (2013) who concluded that more than two-fifth were in the Contemplation Stage of Change (43.8\%), followed by those who were in the Precontemplation Stage of Change (35.8\%), and those who were in the Preparation Stage of Change (20.4\%).

On the other hand, these findings are incongruent with; Tung ${ }^{(9)}$, who concluded that more than a half of the subjects were classified into the Maintenance Stage of Change (55.9\%, followed by those who were in the 
Contemplation Stage (17.6\%), Relapse Stage of Change (14.7\%), Precontemplation Stage of Change (9.8\%), or Action Stage of Change (2\%); Tung ${ }^{(10)}$ who concluded that more than a half of subjects were in the Maintenance SOC, followed by those who are in Precontemplation SOC (17\%), those who are in the Relapse SOC, those who were in the Contemplation SOC (10\%), the Action SOC (3\%). None of subjects were in the Preparation and Relapse risk SOC; Tung ${ }^{(11)}$, who concluded that most of the participants were in the maintenance stage $(60.3 \%)$ and in the Contemplation Stage of Change (25.6\%), with smaller portions in the Action Stage of Change (1.7\%), the Preparation Stage (5.8\%), the Precontemplation Stage (4.1\%), or the Relapse Stage (2.5\%). None of the participants were classified in the relapse risk stage ${ }^{(12)}$ who concluded less than a half (46.3\%) of the subjects were in the Maintenance Stage, followed by those who were in the Precontemplation Stage (18.8\%), those who were in in the Relapse Stage of Change (16.3\%), those who were in the Contemplation Stage of Change (10\%), and Action Stage of Change (8.8\%); Tung ${ }^{(11)}$ who concluded that most of subjects were in Maintenance Stage of Change (60\%), followed by those who were in the Contemplation Stage of Change (26\%), Preparation (6\%), Precontemplation (4\%), Relapse (2\%), and Action Stage of Change (2\%); Tung ${ }^{(12)}$ who concluded that less than a half $(46.3 \%)$ of the subjects were in the Maintenance Stage, followed by those who were in the Precontemplation Stage (18.8\%), those who were in in the Relapse Stage of Change (16.3\%), those who were in the Contemplation Stage of Change (10\%), and Action Stage of Change (8.8\%); Tung ${ }^{(10)}$ who concluded that less than a half $(46.3 \%)$ of the subjects were in the Maintenance Stage, followed by those who were in the Precontemplation Stage of Change (18.8\%), those who were in the Relapse Stage (16.3\%), those who were in the Contemplation Stage of Change (10\%), and those who were in the Action Stage of Change (8.8\%). There was a statistically significant positive correlation between women's age and their Susceptibility to contracting cervical cancer. This finding could be explained as that as women advance in age, they acquire more learning and experiences that enables them to recognize their health and health determinants including reproductive health; particularly the susceptibility to contract cervical cancer. This finding is consistent with that obtained by Cangol and others who concluded that there was a statistically significant difference between women's age and the state of obtaining information about cancer and the state of having the Pap smear test. There was a statistically significant positive correlation between family's socioeconomic status and their Susceptibility to contracting cervical cancer. This finding could be explained as that the better the socioeconomic status the family is, the greater the opportunity to use to unhealthy life style including physical inactivity and unhealthy diet which increase the chance of developing different types of cancer including cervical cancer. There was no statistically significant difference in the Health Belief Model constructs among readiness to Pap smear test groups. This finding reflects that study subjects lack health awareness that can motivate them to adopt health preventive behaviors including Pap smear testing. There was no statistically significant difference in the Health Belief Model constructs among SE status groups. This finding indicates that women; irrespective of their family' socioeconomic status, have invariant, unsound health beliefs which do not motivate them or hinder them from adopting health preventive behaviors. There was no statistically significant difference in the Health Belief Model constructs between access to healthcare services groups. This finding reflects people's dissatisfaction with the quality of healthcare delivery system in Iraq. That is, whether the access to healthcare services was easy or difficult, this doesn't matter for women in terms of seeking the required healthcare services including Pap smear testing. There was a statistically significant difference in women's Perceived Seriousness of cervical cancer among self-rated health status groups. The post hoc analysis using Scheffe test demonstrates that the Perceived Seriousness of cervical cancer scores were higher among women who described their general health as poor.

\section{Conclusion}

1. Most of the women are precontemplators.

2. The older the age, the greater the Susceptibility to contracting cervical cancer.

3. The better the family's socioeconomic status, the greater the greater Susceptibility to contracting cervical cancer.

4. Women's health beliefs do not predict their readiness to Pap smear test.

5. The Perceived Seriousness of cervical cancer scores were higher among women who self-rated health status as poor and vice versa. 


\section{Recommendations:}

1. Education activities to raise awareness need to have cervical screening early.

2. It needs educational activities to increase women's awareness of the risks of cervical cancer.

3. Health education needs to follow a healthy diet and know its impact on cervical cancer, from fitness and a healthy diet

4. Improving the quality of health care services and facilitating access to them.

Conflict of Interest: The researchers confirm that there is no any conflict of interest.

Source of Funding: This study is self-funded.

Ethical Clearance: The researchers obtained the ethical approval from the University of Baghdad, College of Nursing.

\section{References:}

1. Yang H-X, Zhong Y, Lv W-H, Yu H. Factors associated with human papillomavirus infection - findings from a cervical cancer screening program for female employees in Beijing. Cancer management and research [Internet]. 2019 Aug 28 [cited 2020 Nov 3]; 11:8033-41. Available from: https://search-ebscohost-com.ezproxy. okcu.edu/login.aspx?direct=true \& $\mathrm{db}=\mathrm{mnh} \quad \&$ $\mathrm{AN}=31695489$ \& site $=$ ehost-live

2. Schottenfeld D, \& Fraumeni Jr JF. Cancer epidemiology and prevention. Oxford University Press, 2006.

3. Farzaneh E, Heydari H, Shekarchi AA, \& Kamran, A. Breast and cervical cancer-screening uptake among females in Ardabil, northwest Iran: A community-based study. OncoTargets and therapy, 201710, 985.

4. Glanz K, Rimer BK, \& Viswanath K. (Eds.). Health behavior and health education: theory, research, and practice. 2008, John Wiley \& Sons.

5. Abd Ali M BH. Psychometric properties of the Arabic version of The Health Belief Model Scale for Cervical Cancer and the Pap Smear. Unpublished manuscript

6. Krok-Schoen JL, Oliveri JM, Young GS, Katz ML, Tatum CM, Paskett ED. Evaluating the stage of change model to a cervical cancer screening intervention among Ohio Appalachian women. Women \& Health [Internet]. 2016 May [cited 2020 Nov 3];56(4):468-86. Available from: https:// search-ebscohost-com.ezproxy.okcu.edu/login. aspx?direct=true \& $\mathrm{db}=\mathrm{ccm} \& \mathrm{AN}=114607887 \&$ site $=$ ehost-live

7. Kwak M-S, Choi KS, Spring BJ, Park S, Park E-C. Predicting the stages of adoption of cervical cancer screening among Korean women. Preventive Medicine: An International Journal Devoted to Practice and Theory [Internet]. 2009 Aug [cited 2020 Nov 3];49(1):48-53. Available from: https:// search-ebscohost-com.ezproxy.okcu.edu/login. aspx?direct=true \& db=psyh \& AN=2009-11489$007 \&$ site $=$ ehost-live

8. Tung W-C, Granner M, Lu M, Sohn J. Demographics, self-efficacy, benefits/barriers, stages of adopting pap testing among Korean American women. Journal of Obstetrics \& Gynaecology [Internet]. 2019 May [cited 2020 Nov 3];39(4):510-5. Available from: https:// search-ebscohost-com.ezproxy.okcu.edu/login. aspx?direct=true $\& \mathrm{db}=\mathrm{a} 9 \mathrm{~h} \& \mathrm{AN}=135801766 \&$ site $=$ ehost-live

9. Tung W, Lu M, Cook D. Cervical cancer screening among Taiwanese women: a transtheoretical approach. Oncology Nursing Forum [Internet]. 2010 Jul [cited 2020 Nov 3];37(4):E288-94. Available from: https://search-ebscohost-com. ezproxy.okcu.edu/login.aspx?direct=true $\quad \&$ $\mathrm{db}=\mathrm{ccm} \& \mathrm{AN}=105049498 \&$ site $=$ ehost-live

10. Tung W-C, Smith-Gagen J, Lu M, Warfield M. Application of the Transtheoretical Model to Cervical Cancer Screening in Latina Women. Journal of Immigrant \& Minority Health [Internet]. 2016 Oct [cited 2020 Nov 3];18(5):1168-74. Available from: https://search-ebscohost-com. ezproxy.okcu.edu/login.aspx?direct=true \& \& $\mathrm{db}=\mathrm{ccm} \& \mathrm{AN}=119538326$ \& site $=$ ehost-live

11. Tung W-C, Nguyen DHT, Tran DN. Applying the transtheoretical model to cervical cancer screening in Vietnamese-American women. International Nursing Review [Internet]. 2008 Mar [cited 2020 Nov 3];55(1):73-80. Available from: https:// search-ebscohost-com.ezproxy.okcu.edu/login. aspx?direct=true \& db=psyh \& AN=2008-01986$007 \&$ site $=$ ehost-live 